\title{
Effect of Area Specific Minerals Supplementation and Deworming on Productive and Reproductive Performance of Lactating Buffalo
}

\author{
S.C. Kantwa*, Y.K. Meena, S.S. Shekhawat, Ram Pratap, and S.D. Samota \\ Krishi Vigyan Kendra, Jaipur-II, Sri Karan Narendra Agriculture University, Jobner, Jaipur, Rajasthan, INDIA \\ *Corresponding author: SC Kantwa; E-mail: sckantwa.lpm@sknau.ac.in
}

Received: 17 Aug., 2021

Revised: 22 Sept., 2021

Accepted: 28 Sept., 2021

\begin{abstract}
The present study was conducted to demonstrate the effect of area specific mineral mixture supplementation and deworming on the productive, reproductive performance and economics of lactating buffalo. Demonstration was conducted on 200 buffaloes of nearly at the same lactation stage, milk yield and parity selected from three Blocks- namely Kotputli, Viratnagar and Jamuaragarh, District- Jaipur, Rajasthan. Buffaloes were divided in two group; 100 buffaloes were kept in each group viz. control (T1) and demonstrated Group (T2). Two buffaloes of each farmer were selected to maintain similarity in feeding and management practice. Demonstrated Group $\left(\mathrm{T}_{2}\right)$ was fed with area specific mineral mixture @ $50 \mathrm{gm} / \mathrm{buffalo} /$ day till 100 days of early lactation period and 1 ivermectin $\left(80 \mathrm{mg}\right.$ ) bolus, whereas the control group $\left(\mathrm{T}_{1}\right)$ was not supplemented. The data were recorded by the farmers daily in the morning and evening and by the researcher at monthly interval. Analysis of data revealed that supplementation of area specific mineral mixture and ivermectin bolus increased the milk yield by 1.57 litres/ day (17.15\%) in demonstrated group. Similarly, reproductive performance traits such as onset of first estrum after calving, No. of AI required for conception and Service period were also recorded at the same interval between these groups. The B:C ratio of area specific mineral mixture supplementation and ivermectin bolus was observed 1:14.7 under farmer management practices. These findings may suggest that supplementation of area specific mineral mixture and deworming with ivermectin enhanced the productive and reproductive performance for getting higher return and sustainable profit from buffalo farming.
\end{abstract}

\section{HIGHLIGHTS}

(0 Parasitic infestation influences feed intake, weight gain, milk production and reproductive performances of buffalo.

o Supplementation of minerals and deworming increases milk yield and animal health.

Keywords: Buffalo, Deworming and Mineral mixture

India has the largest buffalo population in the world and ranks first in milk production (187.75 million) during 2018-19. The per capita milk availability in the country is 394 gram/day which is much more than the world average consumption of milk 302 gram/day (BAHS). However, per animal productivity is very low in the country is mainly due to poor genetic makeup along with compromised nutritional status of the dairy animals which leads to various metabolic disorders and reproductive inefficiencies such as anestrous, repeat breeding, and infertility (Bach, 2019). Hence, balanced nutrition is very essential for maintaining good body condition score ( 3 to 3.5 ) which render them enhancing the production and reproduction efficiency of dairy animals. Mineral deficiency in dairy animals is the foremost cause of poor growth rate; suppress body immunity, decreased milk yield, and various reproductive disorders (Bindari et al., 2013). Mineral deficiencies or soil or forage imbalances have long been held responsible for low production and poor reproductive performance in tropical and subtropical agro-climatic conditions among

How to cite this article: Kantwa, S.C., Meena, Y.K., Shekhawat, S.S. Pratap, R. and Samota, S.D. (2021). Effect of Area Specific Minerals Supplementation and Deworming on Productive and Reproductive Performance of Lactating Buffalo. J. Anim. Res., 11(05): 843-848. Source of Support: None; Conflict of Interest: None 
cattle and buffaloes fed on crop residues (Singh et al., 2020). A large number of livestock in the tropics suffer from deficiencies or imbalances in mineral nutrition. Minerals are essential for growth and reproduction and are involved in a large number of digestive, physiological and biosynthetic processes in the body. Animal obtain minerals through the consumption of natural feeds, fodders and supplementation of inorganic salts as mineral mixture in the ration. Minerals are supplied to the livestock through mineral mixture in the inorganic form. One of the major disadvantages of using such supplements is that the minerals from such sources are not fully absorbed due to antagonism and anti-nutritional factors present in the diet. In addition, higher levels of inorganic salt based mineral mixture resulted in increased excretion, which may cause environmental pollution. Increase in milk yield and reproductive efficiency as a result of area-specific mineral mixture supplementation recorded in some parts of India (Singh et al., Bhuvaneswari, 2019). Parasitic infestation has been considered as one of the major constraint of livestock production. There are two types of parasites, i.e., internal and external of which internal parasites are more devastating for farm animals. Parasitic infestation reduces feed intake remarkably as a consequence growth and production performances of cattle hampered. Parasitism is also responsible for reduced performance such as reduced milk production and reproductive performances. The present study was conducted in lactating buffaloes maintained under a semi-intensive management system in Jaipur district of Rajasthan State, India, under field conditions. Therefore, the present investigation was conducted to demonstration of area specific mineral mixture supplementation and deworming with ivermectin on productive and reproductive performance of lactating buffalo.

\section{MATERIALS AND METHODS}

The present study was conducted under front line demonstration laid out during 2018-19 and 2019-20 in three Blocks- namely Kotputli, Viratnagar and Jamuaragarh, District- Jaipur, Rajasthan to demonstrate of area specific mineral mixture supplementation and deworming with ivermectin on the productive, reproductive performance and economics of lactating buffaloes under farmer management practices. Every year, 100 buffalo were selected to carry out this study. All the buffaloes were free from physiological and anatomical disorder and recently calved. A total of 200 lactating buffaloes of nearly at the same lactation stage, milk yield and parity were selected of 100 farmers. To maintain similarity in feeding and management practices, two buffaloes of each farmer were selected and one buffalo was kept as control $\left(T_{1}\right)$ and another was supplemented with area specific mineral mixture, deworming with ivermectin and considered as demonstrated group $\left(\mathrm{T}_{2}\right)$. Thus, a total 100 buffaloes kept in demonstrated group and 100 kept under control group. All the buffaloes were managed under farmer's management practices. The feeding of 5-6 $\mathrm{kg}$ dry fodder, $25-30 \mathrm{~kg}$ green fodder and $6-7 \mathrm{~kg}$ concentrate per day per buffalo in both groups. The composition of the concentrate for both buffalo groups was similar. The concentrate was offered two times a day just before milking in morning and evening. In demonstrated group $\left(\mathrm{T}_{2}\right)$ in addition to above $50 \mathrm{gm}$ area specific mineral mixture per buffalo was supplemented continuously from the day one after calving to 100 days and deworming with one bolus $(80 \mathrm{mg}$ ) ivermectin 5 days after calving. A training programme was conducted for the farmers before starting the demonstration to educate them for correct method of data recording on different parameters. The daily milk yield was recorded in morning and evening by the farmers in a diary and at monthly interval by the researcher. The data on onset of first post - partum estrus and no. of inseminations required for conception were recorded on the basis of dairy buffalo owner's response. The demonstration was conducted for a period of 100 days. The data were analyzed through GLM procedure. The liner model was used for all variables using least square analysis of variance. In the present fixed factors were treatments $\left(\mathrm{T}_{1}-\right.$ Control group and $\mathrm{T}_{2}$ Demonstrated group). The statistical analysis was carried out using SPSS software program, version 14.0. The level of statistical significance was set at $\mathrm{P}<0.05$.

\section{RESULTS AND DISCUSSION}

The results and discussions of the present study have been presented under following sub heads:

\section{Milk production parameter}

Milk production parameters of lactating buffalo in the demonstrated group $\left(\mathrm{T}_{2}\right)$ and control group $\left(\mathrm{T}_{1}\right)$ have been presented in table 1 . 
Table 1: Effect of area specific mineral mixture supplementation and deworming on milk production of lactating buffalo

\begin{tabular}{lllllll}
\hline \multirow{2}{*}{ Treatment } & \multicolumn{3}{c}{ Average milk yield (lit/day/buffalo) } & \multicolumn{3}{c}{ 100 day total milk yield (lit) } \\
\cline { 2 - 7 } & $\mathbf{2 0 1 8 - 1 9}$ & $\mathbf{2 0 1 9 - 2 0}$ & Pooled & $\mathbf{2 0 1 8 - 1 9}$ & $\mathbf{2 0 1 9 - 2 0}$ & Pooled \\
\hline $\mathrm{T}_{1}$ (Control group) & 9.10 & 9.21 & 9.16 & 910.00 & 921.00 & 915.50 \\
$\mathrm{~T}_{2}$ (Demonstrated Group) & 10.75 & 10.70 & 10.73 & 1075.00 & 1070.00 & 1072.00 \\
SEM & 0.13 & 0.13 & 0.09 & 13.37 & 13.06 & 9.31 \\
P value & $<0.01$ & $<0.01$ & $<0.01$ & $<0.01$ & $<0.01$ & $<0.01$ \\
Level of significance & $*$ & $*$ & $*$ & $*$ & $*$ & $*$ \\
\hline
\end{tabular}

$* \mathrm{P}<0.01$.

Table 2: Effect of area specific mineral mixture supplementation and deworming on reproduction of lactating buffalo

\begin{tabular}{|c|c|c|c|c|c|c|c|c|c|}
\hline \multirow[t]{2}{*}{ Treatment } & \multicolumn{3}{|c|}{$\begin{array}{c}\text { Onset of first estrus after calving } \\
\text { (Days) }\end{array}$} & \multicolumn{3}{|c|}{$\begin{array}{c}\text { No. of AI/service required for } \\
\text { conception }\end{array}$} & \multicolumn{3}{|c|}{ Service period (days) } \\
\hline & 2018-19 & 2019-20 & Mean & 2018-19 & 2019-20 & Mean & 2018-19 & 2019-20 & Mean \\
\hline $\mathrm{T}_{1}$ (Control group) & 122.06 & 123.62 & 122.84 & 2.62 & 2.36 & 2.49 & 179.70 & 175.54 & 177.62 \\
\hline $\mathrm{T}_{2}$ (Demonstrated Group) & 96.5 & 98.2 & 97.35 & 1.88 & 1.72 & 1.80 & 137.86 & 136.04 & 136.95 \\
\hline SEM & 1.63 & 1.59 & 1.14 & 0.12 & 0.11 & 0.08 & 2.99 & 2.86 & 2.06 \\
\hline$P$ value & $<0.01$ & $<0.01$ & $<0.01$ & $<0.01$ & $<0.01$ & $<0.01$ & $<0.01$ & $<0.01$ & $<0.01$ \\
\hline Level of significance & $*$ & $*$ & $*$ & $*$ & $*$ & $*$ & $*$ & $*$ & $*$ \\
\hline
\end{tabular}

$* \mathrm{P}<0.01$.

The pooled average milk yield during the trial period was observed $10.73 \pm 0.09$ and $9.16 \pm 0.09$ litre/day/buffalo in demonstrated and control group, respectively. It indicates that the average milk yield of buffalo in demonstrated group was significantly higher $(\mathrm{P}<0.01)$ as compared to control group. Similar results were also reported by Rathore et al. (2017) significantly increase milk production in buffalo during supplementing mineral mixture and deworming. Similar findings were also observed by Riad et al. (2018) and Somkuwar et al. (2011), an increase in milk production in dairy animals during the supplementation of chelated minerals. Kumar et al. (2020); Singh et al. (2020); Bhuvaneswari (2019) and Gupta et al. (2017) showed that the after supplementation of area specific mineral mixture and trace minerals to dairy animals, which were associated with increased milk yield. Beside this among the two groups, demonstrated group were also produced significantly $(\mathrm{P}<0.01)$ higher mean pooled total milk yield (1072.00 litre) for 100 days than the control group (915.50 lit). Pal et al. (2020), Gupta et al. (2017) and Noeek et al. (2006) has also found higher milk yield in mineral supplementation group of dairy animals. Average daily milk yield and total milk yield was found higher in demonstrated group over control group by 17.15 per cent. Similar results were also reported by Rathore et al. (2017). Gupta et al. (2017) and Singh et al. (2016) also observed same result of increases milk production in mineral supplemented dairy animals. The present results indicating that deworming and supplementing of area specific mineral mixture could increase milk yield of buffaloes due to having impact on the milk production cells in the udder. Their micro and macro element contribute in the working of memory cell to enhance their production (Pal et al., 2020). These finding is in full agreement with the observations of Gupta et al. (2017).

\section{Reproductive parameter}

Reproductive traits i.e. Onset of first estrus after calving, No. of AI required for conception and service period were also recorded during the demonstration period as shown in table 2 . These reproductive traits significantly $(\mathrm{P} \leq 0.01)$ differed in the Demonstrated group $\left(\mathrm{T}_{2}\right)$ of dairy animals with the control group $\left(\mathrm{T}_{1}\right)$.

The pooled average onset of first estrus after calving was lower (97.35 days) in treated group as compare to control group (122.84 days), which shows significant difference 
$(\mathrm{P}<0.01)$. These findings are also accordance of Singh et al. (2020), Kumar et al. (2020), Tanwar et al. (2019) and Gupta et al. (2017) also observed lower post-partum estrous in mineral mixture supplemented group than control. On average onset of first postpartum estrus was observed to occur 25.49 days earlier in the demonstrated group as compared to control. Similar findings were also reported by Tanwar et al. (2019) in buffaloes.

The number of pooled mean Artificial Insemination/Natural service required for conception was lower in demonstrated group (1.80) as compared to control group (2.49). The number of A.I/Natural service required per conception was also significantly $(\mathrm{P}<0.05)$ lower in demonstrated group as compared to control group. Similar findings were also reported by Tanwar et al. (2019), Bhuvaneswari (2019) and Gupta et al. (2017), there was a significant difference of a number of $\mathrm{AI} /$ conception between mineral mixture supplemented and non supplemented group in dairy animals.

The pooled average service period was observed $136.95 \pm 2.06$ days in demonstrated group and 177.62 \pm 2.06 days in control group. It was also found significantly $(\mathrm{P}<0.05)$ lower in buffaloes supplemented with area specific mineral mixture and deworming with ivermectin as compare to control group buffaloes. The present findings are in conformity with the results of Rathore et al. (2017) who reported that mineral supplementation and deworming have positive effect on reduces service period of buffaloes. Similar findings were also reported by Singh et al. (2020), Kumar et al. (2020), Tanwar et al. (2019) and Gupta et al. (2017), there was a significant difference of service period between mineral mixture supplemented and non supplemented group in dairy animals. 41.67 days higher service period in control group reduces the profit of farmer from buffalo rearing. The improvement in reproductive performance of buffaloes due to area specific mineral supplementation and deworming as compared to the performance of non supplemented group was very clear.

\section{Economics of area specific mineral mixture supplementation and deworming with ivermectin}

A partial budget analysis measures was used in those items of expenditure and income. Therefore, the cost of fodder, concentrate feed, mineral mixture and ivermectin bolus have been considered. The cost of labour was not considered for calculation because it was same in both groups as family members were used in management of livestock.

Economics of supplemented area specific mineral mixture and deworming of lactating buffaloes in the demonstrated group $\left(\mathrm{T}_{2}\right)$ and control group $\left(\mathrm{T}_{1}\right)$ have been presented in table 3 . Economic analysis of the data showed that deworming with ivermectin and supplementation of area

Table 3: Economics of supplemented area specific mineral mixture and deworming in lactating buffaloes

\begin{tabular}{|c|c|c|c|c|c|c|}
\hline \multirow{2}{*}{ Para meters } & \multicolumn{3}{|c|}{$T_{1}($ Control group) } & \multicolumn{3}{|c|}{$\mathbf{T}_{2}$ (Demonstrated Group) } \\
\hline & 2018-19 & 2019-20 & Mean & 2018-19 & 2019-20 & Mean \\
\hline Average milk yield (Lit/day/buffalo) & 9.10 & 9.21 & 9.16 & 10.75 & 10.70 & 10.73 \\
\hline Rearing cost (₹/day/buffalo) & 180 & 180 & 180 & 184 & 184 & 184 \\
\hline Average rearing cost per litre of milk production (₹) & 19.78 & 19.54 & 19.65 & 17.12 & 17.20 & 17.15 \\
\hline Gross return (₹/day/buffalo) & 364 & 368 & 366 & 430 & 428 & 429 \\
\hline Net return (₹/day/buffalo) & 184 & 188 & 186 & 246 & 244 & 245 \\
\hline $\mathrm{B}: \mathrm{C}$ & 2.02 & 2.05 & 2.03 & 2.34 & 2.33 & 2.33 \\
\hline $\begin{array}{l}\text { Additional milk yield by supplementing area specific mineral } \\
\text { mixture and deworming (Lit/day) }\end{array}$ & - & - & - & 1.65 & 1.49 & 1.57 \\
\hline Milk yield increase over control (\%) & - & - & - & 18.13 & 16.18 & 17.15 \\
\hline Value of additional milk (₹) & - & - & - & 66.00 & 59.60 & 62.80 \\
\hline $\begin{array}{l}\text { Cost of area specific mineral mixture supplementation and } \\
\text { Ivermectin bolus ( } ₹ / \text { day/buffalo) }\end{array}$ & - & - & - & 4 & 4 & 4 \\
\hline $\begin{array}{l}\mathrm{B}: \mathrm{C} \text { ratio for supplementing area specific mineral mixture and } \\
\text { deworming }\end{array}$ & - & - & - & 15.5 & 13.9 & 14.7 \\
\hline
\end{tabular}


specific mineral mixture enhances the pooled mean milk yield by $17.15 \%$ per day in demonstrated group. The mean rearing cost of per litre of milk was lower (₹ 17.15) in demonstrated group as compared to control group (₹ 19.65) which showed that dietary supplementation of area specific mineral mixture and deworming under field condition reduced the cost of milk production sizably. Average gross return (₹/day/buffalo) was 429 and 366 demonstrated and control group, respectively and mean net profit per litre of milk was found higher in demonstrated group (₹ 245 day/buffalo) than control group (₹ $186 /$ day/buffalo). The mean benefit-cost ratio was also found higher in demonstrated group (2.33) as compared to control (2.03). It was observed that buffalo rear farmer getting mean milk yield 1.57 litres and ₹ 62.80 additional per day by deworming and supplementing area specific mineral mixture. Mean benefit-cost ratio of supplementing area specific mineral mixture and deworming was 1:14.7. Similar result to the present finding was in accordance with Rathore et al. (2017), Tanwar et al. (2019) and Singh et al. (2020) in dairy animals.

\section{CONCLUSION}

It can be concluded from the present study that supplementation of area specific mineral mixture and deworming to the lactating buffaloes under field conditions not only increases the milk yield, but also reduce post-partum estrus period, number of A.I/service per conception, service period, cost of per litre of milk production and consequently improving socio-economic conditions. Hence, it is needed to awareness created among the dairy farmers to supplement the area specific mineral mixture and deworming to their animals to get more profit from dairy animal farming.

\section{ACKNOWLEDGEMENTS}

The authors are thankful to ICAR-Agriculture Technology Application Research Institute, Zone II, Jodhpur, Rajasthan, for providing the fund to conduct the study as front line demonstration (FLD) through KVK and Directorate of Extension Education, Sri Karan Narendra Agriculture University, Jobner, Jaipur, Rajasthan for encouragement, technical support and providing facilities for conducting the demonstration.

\section{REFERENCES}

Bach, A. 2019. Effects of nutrition and genetics on fertility in dairy cows. Reprod. Fertil. Dev., 31: 40-54.

BAHS, 2019. Basic Animal Husbandry Statistics.

Bhuvaneswari, S.S.B. 2019. Assessment of area specific mineral mixture supplementation. Int. J. Res. Analy. Rev., 6(2): 546549 .

Bindari, Y.R., Shrestha, S., Shrestha, N. and Gaire, T.N. 2013. Effects of nutrition on reproduction-A review. Adv. Appl. Sci. Res., 4(1): 421-429.

Gupta, R., Singh, K., Sharma, M. and Kumar, M. 2017. Effect of mineral mixture feeding on the productive and reproductive performance of crossbred cattle. Int. J. Livest. Res., 7(12): 231-236.

Kumar, R., Rana, D.S., Kumari, R., Gupta, R. and Singh, M. 2020. Effect of area specific mineral mixture feeding on productive and reproductive performance of dairy animals. $J$. Entom. Zool. Stud., 8(4): 2407-2409.

Noeek, J.E., Socha, M.T. and Tomlinson, D.J. 2006. The effect of trace mineral fortification level and source on performance of dairy cattle. J. Dairy Sci., 89(7): 2679-2693.

Pal, K., Maji, C., Das, M.K., Banerjee, S., Saren, S. and Tudu, B. 2020. Effects of area specific mineral mixture (ASMM) supplementation on production and reproductive parameters of crossbred and desi cows: a field study. Res. Bioti., 2(2): $55-60$.

Rathore, R.S., Verma, R.K., Dayanand and Mehta, S.M. 2017. Effect of Mineral Supplementation and Dewormer on Service Period and Milk Production in Buffaloes under Field Conditions. Ann. Arid Zone, 56(1\&2): 47-50.

Riad, W.A. Ghada S. EL-Esawy, A.M.A. Mohy EL-Dein, M.F.E. Ali and H.M.A. Gaafar. 2018. Effect of supplementary chelated zinc and manganese methionine on productive and reproductive performance of Friesian cows. Egyp. J. Agri. Res., 96(1): 289-301.

Singh, N.M., Tripathi, A.K., Saikia, R., Medhi, K., Gogoi, S.H., Gogoi, P., Thaosen, J., Langthasa, S., Mandal, D.K. and Hojai, N. 2020. Effect of area specific mineral mixture supplementation on milk yield and reproductive traits of crossbred dairy cattle under sub-tropical region of north eastern India. Int. J. Chem. Stud., 8(6): 2239-2243.

Singh, S., Chhabra, S., Singh, C., Randhawa, S.S., Gupta, D.K. 2016. Effect of area specific mineral mixture feeding on milk yield and composition of dairy animals of central Zone of Punjab, Int. J. Livst. Res., 6(3): 62-65. 
Somkuwar, A.P., Kadam, A.S, Shiva, K. and Radhakrishna, P. M. 2011. Efficacy study of metho-chelated organic minerals preparation feeding on milk production and fat percentage in dairy cows. Vet. World, 4(1): 19-21.
Tanwar, P.S., Verma, H.K. and Jadoun, Y.S. 2019. Effect of mineral supplementation on production and reproduction performance of buffaloes under farmer management practices. Int. J. Agri. Sci., 11(1): 7707-7709. 